\title{
GABA tea extract inhibit the colony formation and invasion of colorectal cancer cells
}

\author{
Abstract \\ Objectives: The study is aim at evaluating the effects of GABA tea on colorectal \\ cancer cell proliferation, colony formation and invasion. \\ Methods: Colorectal cancer cell line HT-29 treated with GABA tea extract \\ $(12.5 \sim 200 \square \mathrm{g} / \mathrm{mL}$ ) were assessed for viability by MTT assay and for their invasion \\ potential by evaluating their ability to penetrate through a matrix gel-coated Boyden \\ chamber. \\ Results: GABA tea extract exhibited slight effect on cell proliferation of HT-29. The \\ colony formation was inhibited in both culture plate and Boyden chamber. \\ Conclusions: GABA tea extract inhibited the colony formation and invasion of \\ colorectal cancer cells. GABA tea is a potential adjuvant agent for colorectal cancer \\ therapy. \\ Keywords: GABA tea; colorectal cancer, colony formation, invasion, colorectal \\ carcinoma
}

Volume 5 Issue 4 - 2017

\author{
Chih Cheng Lin,' Yuan Chiang Chung, ${ }^{2}$ Chih \\ Ping $\mathrm{Hsu}^{3}$ \\ 'Department of Biotechnology and Pharmaceutical Technology, \\ Yuanpei University of Medical Technology, Taiwan \\ 2Department of Surgery, Cheng-Ching Hospital,Taiwan \\ ${ }^{3}$ Department of Medical Laboratory Science and Biotechnology, \\ Yuanpei University of Medical Technology, Taiwan
}

\begin{abstract}
Correspondence: Chih Ping Hsu, Department of Medical Laboratory Science and Biotechnology, Yuanpei University of Medical Technology, Taiwan, No. 306 Yuanpei Street, Hsinchu City, 30015 Taiwan, ROC, Tel +886 36108166 , Fax +886 36102312 , Email hsucp@mail.ypu.edu.tw
\end{abstract}

Received: November 01, 2017 | Published: December 22, 2017

\section{Background}

Colorectal carcinoma (CRC) became the most prevalent cancer over hepatocellular carcinoma in Taiwan from 2007. ${ }^{1}$ CRC could progress to become invasive and metastatic malignant cells. ${ }^{2}$ Tea extract have been shown to reduce the risk of many diseases, including CRC. ${ }^{3-8}$ GABA tea is a special tea that contains $\gamma$-aminobutyric acid and is famous on its promoted effect on sleeping. Recently, GABA tea has been shown containing rich amount polyphenols. High level of GABA in tumor tissues is associated with longer survival in breast cancer patients, indicating the prognosis value of GABA. ${ }^{9}$ However, there is no evidence that GABA tea extract could modulate the growth of CRC cells. Here, we used HT-29 as modeling cells and test the effect of GABA tea extract on cell proliferation, colony formation and invasion.

\section{Methods}

\section{Cell proliferation assay}

HT-29cells were plated at 10,000cells per well in 96-well plate. After $18 \mathrm{~h}$ of culture, cells were treated with GABA tea extract and stained with MTT after 48hour treatment. Data were obtained from the averages of three independent experiments.

\section{Clonogenic growth assay}

200cells were seeded in a 6-well plate and treated with GABA tea extract then incubated at $37^{\circ} \mathrm{C}$ for 14 days. The colonies were fixed in $70 \%$ ethanol and stained with $0.2 \%$ crystal violet. Colonies of $>50$ cells were counted and the colony-forming potential of GABA tea-treated cells was expressed as the percentage of colonies of the untreated cells.

\section{Invasion assays}

The invasion assay was carried out in modified Boyden's chambers constructed using multi-well cell-culture plates and inserts (Falcon, Lincoln Park, NJ, USA). $5 \times 10^{4}$ cells were added to the upper chamber with different concentrations of GABA tea extract in culture medium and were incubated at $37^{\circ} \mathrm{C}$ for 5 days. The colonies that invaded the basement membrane into the lower chamber were fixed, stained with $0.2 \%$ crystal violet, and counted in 10 randomly-selected microscopic fields (x100).

\section{Results and discussion}

The proliferation of HT-29 was slightly suppressed by GABA tea extract treatment but there was no significant difference between untreated control and the treated cells (Figure 1). Colony formation showed the inhibiting effect of GABA tea extract on HT-29 cell growth, and the colonies were decreased in HT-29 cells treated with up to $12.5 \mu \mathrm{g} / \mathrm{mL}$ GABA tea extract. The inhibition effect seems to be sustained at the level of $~ 50 \%$ up to $50 \mu \mathrm{g} / \mathrm{mL}$ GABA tea extract (Figure 2). The results indicated that GABA tea extract exerts an inhibiting effect on CRC cells by means of colony formation. Since colony forming activity is strongly associated with the tumorigenesis of the tumor cells in vivo, this result implicated that GABA could represent the inhibition potential of CRC tumor growth. GABA tea extract also inhibited the invasion potential, as shown in Figure 3, the number of invading cells was gradually decreased after treating with up to $12.5 \mu \mathrm{g} / \mathrm{mL}$ GABA. The invasiveness of HT-29 seems to be suppressed by treatment of GABA, implicating the inhibiting effect on the malignant potential of GABA tea extract.

In conclusion, this study demonstrates that GABA tea treatment inhibits colony formation and invasion/metastasis in CRC HT29 cells. GABA tea extract also decreased invasion potential of HT- 
29cells. Taken together, we suggest GABA tea could be a potential chemopreventive or therapeutic agent for CRC.

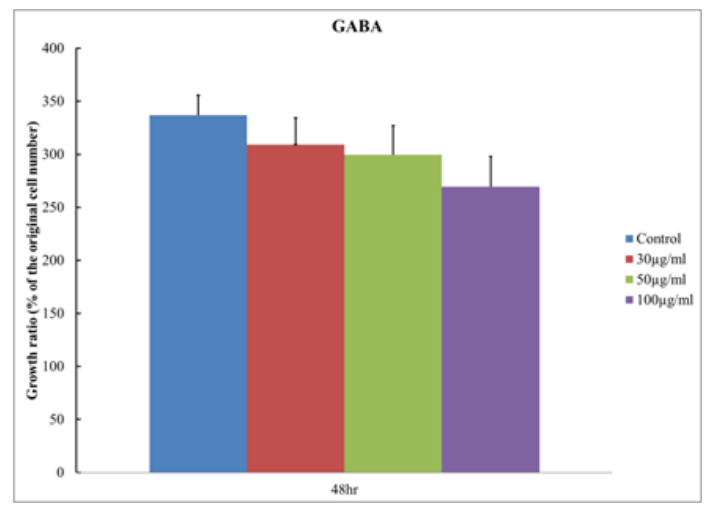

Figure I Influence of the proliferation by GABA tea extract in HT-29cells. HT-29cells ( $\left.1 \times 10^{4}\right)$ were treated with increasing concentrations of GABA tea extract as indicated then incubated at $37^{\circ} \mathrm{C}$ for $48 \mathrm{~h}$. Viable cells were stained with MTT and counted under a spectrophotometer, and cell viability was expressed as the percentage of untreated cells. The data reported are the averages of three independent experiments and are expressed as means $\pm S D$.

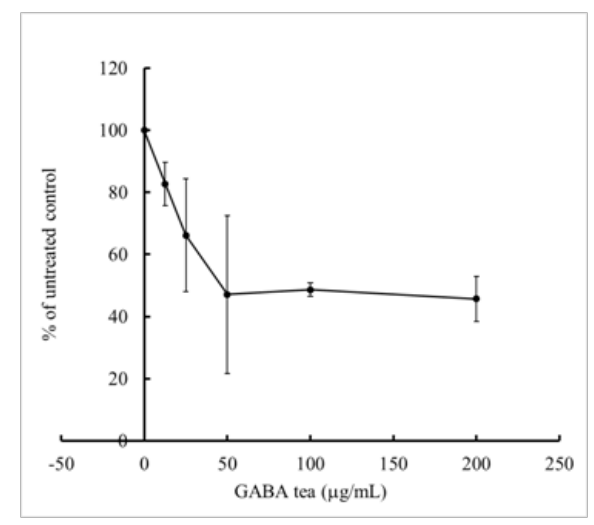

Figure 2 Inhibition of the colony formation by GABA tea extract in HT-29cells. A total of $200 \mathrm{HT}$-29cells were directly seeded in 6-well plate as described in Methods and treated with different concentrations of GABA tea extract as indicated. Colonies of more than 50cells were counted under a microscope and are expressed as the percentage of untreated cells. The data reported are the averages of three independent experiments and are expressed as means \pm SD.

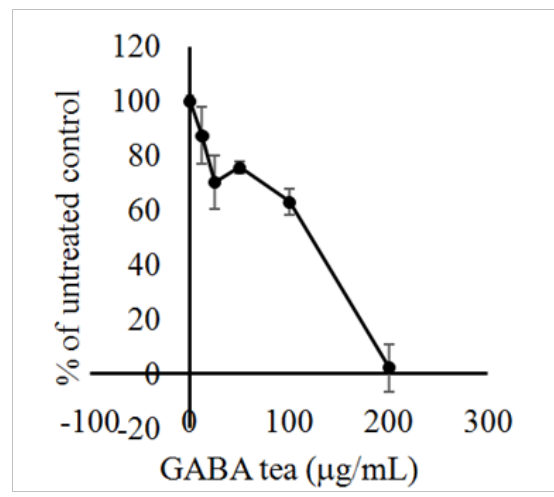

Figure 3 Inhibition of invasion by by GABA tea extract in HT-29cells. Cells were seeded into the matrix-gel-coated upper side of a Boyden chamber and treated with different concentrations of GABA tea extract as indicated for 5 days. The cells penetrating into the lower side of the Boyden chamber were stained and counted under a microscope. The data reported are the averages of three independent experiments. 


\section{Acknowledgements}

None.

\section{Conflicts of interest}

The author declares no conflict of interest.

\section{References}

1. HPA. Taiwan Health Promotion Administration (HPA), Ministry of Health and Welfare. Health and Vital Statistics; 2013.

2. Price P, Sikora K, Illidge T. Treatment of Cancer Hodder Arnold. London; 2008.

3. Ariga T. The antioxidative function, preventive action on disease and utilization of proanthocyanidins. Biofactors. 2004;21(1-4):197-201.

4. Bagchi D, Bagchi M, Stohs SJ, et al. Free radicals and grape seed proanthocyanidin extract: importance in human health and disease prevention. Toxicology. 2000;148(2-3):187-197.
5. Halliwell B. Antioxidants and human disease: a general introduction. Nutr Rev. 1997;55(1 Pt 2):S49-S52.

6. Milner JA, McDonald SS, Anderson DE, et al. Molecular targets for nutrients involved with cancer prevention. Nutr Cancer. 2001;41(1-2):116.

7. Soong YY, Barlow PJ. Isolation and structure elucidation of phenolic compounds from longan (Dimocarpus longan Lour.) seed by highperformance liquid chromatography-electrospray ionization mass spectrometry. J Chromatogr A. 2005;1085(2):270-277.

8. Surh YJ. Cancer chemoprevention with dietary phytochemicals. Nat Rev Cancer. 2003;3(10):768-780.

9. Brzozowska A, Burdan F, Duma D, et al. $\gamma$-amino butyric acid (GABA) level as an overall survival risk factor in breast cancer. Ann Agric Environ Med. 2017;24(3):435-439. 